\title{
Clinical implications of tumor necrosis factor receptor 2 in breast cancer
}

\author{
FUQIAN YANG $^{1 *}$, ZHONGHUA ZHAO $^{2 *}$ and NANA ZHAO ${ }^{3}$ \\ ${ }^{1}$ Department of Breast Surgery, Weifang People's Hospital, Weifang, Shandong 261041; \\ ${ }^{2}$ Department of Oncology, The Affiliated Hospital of Binzhou Medical College, Binzhou, Shandong 256600; \\ ${ }^{3}$ Department of Medical Examination, Fangzi People's Hospital, Weifang, Shandong 261000, P.R. China
}

Received February 4, 2016; Accepted March 3, 2017

DOI: $10.3892 / \mathrm{ol} .2017 .6410$

\begin{abstract}
Tumor necrosis factor receptor 2 (TNFR2) is a member of the tumor necrosis factor receptor family. Its high expression and oncogenic roles have been reported in several types of tumors in previous years. However, the clinical implication of TNFR2 in breast cancer (BC) tissue (i.e., not soluble TNFR2 in blood or genetic variation of TNFR2) has not been reported. In the present study, TNFR 2 expression was detected in BC tissue using immunohistochemistry and, to the best of our knowledge, it was confirmed for the first time that TNFR2 was positively associated with increased tumor size, advanced clinical stage and higher pathological grade. Survival analysis revealed that TNFR2 was positively associated with shorter overall survival (OS) time and disease-free survival (DFS) time. In addition, univariate regression analysis demonstrated that TNFR2 expression $(\mathrm{P}=0.045)$, tumor size $(\mathrm{P}<0.0001)$, clinical stage $(\mathrm{P}<0.0001)$, pathological grade $(\mathrm{P}=0.002)$, estrogen and progesterone receptor and human epidermal growth factor receptor 2 (HER2) triple-status $(\mathrm{P}=0.001)$ all had a significant impact on the OS rate of patients with $\mathrm{BC}$. TNFR2 expression $(\mathrm{P}=0.017)$, age $(\mathrm{P}=0.011)$, menopausal status $(\mathrm{P}<0.0001)$, tumor size $(\mathrm{P}=0.016)$, clinical stage $(\mathrm{P}=0.005)$, pathological grade $(\mathrm{P}=0.002)$ and estrogen/progesterone receptor and HER2 triple-status $(\mathrm{P}=0.008)$ were all shown to significantly impact the DFS rate of patients with $\mathrm{BC}$. Multivariate regression analysis showed that only clinical stage $(\mathrm{P}=0.024)$, estrogen and progesterone receptor status and HER2 status $(\mathrm{P}=0.009)$ had a significant impact on the OS rate of patients with $\mathrm{BC}$, while TNFR2 expression $(\mathrm{P}=0.043)$ and menopausal status $(\mathrm{P}=0.033)$ were shown to significantly
\end{abstract}

Correspondence to: Mrs. Nana Zhao, Department of Medical Examination, Fangzi People's Hospital, 80 Gong'an Street, Fangzi, Weifang, Shandong 261000, P.R. China

E-mail: drqiangliwf@163.com

*Contributed equally

Key words: tumor necrosis factor receptor 2, breast cancer, immunohistochemistry, overall survival, disease-free survival impact the DFS rate of patients with BC. These data indicated that TNFR2 may perform important roles in the progression and prognosis of $\mathrm{BC}$. This enriches previous understanding about TNFR2 in BC.

\section{Introduction}

Breast cancer $(\mathrm{BC})$ is one of the most common female malignant tumors in the world, with increasing incidence (1). As increasing attention has been paid to early detection in previous years, numerous precancerous diseases, including atypical ductal hyperplasia, ductal carcinoma in situ and atypical lobular hyperplasia, may be treated prior to malignant transformation (2). However, with the development and combination of traditional therapy methods, including surgery, chemotherapy and radiotherapy, molecular target therapy and endocrine therapy have also contributed to a breakthrough in cancer therapy, and may ameliorate prognosis significantly (3-7). However, at present, there remains $\sim 500,000$ BC-associated mortalities worldwide every year, which is increasing (8). Therefore, it is necessary to identify more effective molecular targets for the diagnosis and treatment of BC.

Tumor necrosis factor receptor 2 (TNFR2) is a member of the tumor necrosis factor receptor family (9). TNFR2 is composed of membrane binding TNFR2 and soluble TNFR2 (sTNFR2). It was initially identified in hematopoietic cells and endothelial cells, and is involved in anti-inflammation, immune regulation, the repair of lung injury induced by lipopolysaccharide and the healing of bone fracture (10-12). The high expression of TNFR2 and its pro-progression roles have been previously reported in various types of tumor, including skin tumors, cholangiocarcinoma, myeloma, colorectal cancer and non-Hodgkin lymphoma (13-17). However, in BC, clinical studies about TNFR2 were mainly focused on STNFR2 in the blood, and the clinical implication of TNFR2 in BC tissue remains limited $(18,19)$. To the best of our knowledge, the association between TNFR2 in BC tissue with clinical parameters and prognosis has not yet been reported.

In the present study, TNFR2 expression was detected in BC tissue using immunohistochemistry (IHC) and, to the best of our knowledge, the results showed for the first time that patients with high TNFR2 were characterized by increased tumor size, advanced clinical stage, higher pathological grade 
and poorer overall survival (OS) rate and disease-free survival (DFS) rate. In addition, univariate and multivariate Cox regression analysis detected the impacts of clinical parameters on OS and DFS rate.

\section{Materials and methods}

Patient selection. Following approval by the review board and ethics committee of Weifang People's Hospital (Weifang, China), 125 primary BC specimens were selected from patients who underwent surgical resection between January 2005 and December 2010 at Weifang People's Hospital. No patients received chemotherapy, radiotherapy, immunomodulatory therapy or hormonal therapy prior to surgery, or by the time of follow-up. Follow-up data was summarized on December 31th, 2015. The information of patients is shown in Table I.

$I H C$. Sections were cut into $3-\mu \mathrm{m}$ slices and incubated with primary antibodies for TNFR2 (rabbit anti-human; dilution, 1:300; cat. no. 3727; Cell Signaling Technology, Inc., Danvers, MA, USA) at $4^{\circ} \mathrm{C}$ overnight. Normal rabbit immunoglobulin G ( $\operatorname{IgG})$, instead of antibodies, was used as the negative control. The sections were then incubated with horseradish peroxidase goat anti-rabbit IgG polymer (ready-to-use dilution; cat. no. 9902; Maixin Biotechnology Development Co., Ltd., Fuzhou, China) and stained with 3,3'-diaminobenzidine (cat. no. ZLI-9017; ZSGB-BIO, Beijing, China); cell nuclei were stained using hematoxylin (cat. no. ZLI-9609; ZSGB-BIO). The scores were evaluated a CX31 microscope (Olympus corporation, Tokyo, Japan) by two pathologists (magnification, $\mathrm{x} 400$ ). The proportion of stained cells was recorded in at least 5 random fields. The proportion score represented the fraction of positively stained tumor cells $0,<10 \% ; 1,10-25 \% ; 2$, $26-75 \% ; 3,>75 \%)$. The intensity score represented the average staining intensity 0 , none; 1 , weak; 2 , intermediate; 3 , strong). The expression score of TNFR2 was calculated as the product of the proportion and intensity scores. Scores $\geq 4$ were classified as high expression, while scores $<4$ were classified as low expression.

Statistical analysis. SPSS 11.0 software (SPSS, Inc., Chicago, IL, USA) was used for statistical analysis. The association between the expression of TNFR 2 and clinical parameters was analyzed using the $\chi^{2}$ test. Survival curves were drawn using the Kaplan-Meier method and compared using the log-rank test. Cox's proportional hazards regression model was performed to identify factors affecting the OS and DFS rate of $\mathrm{BC} . \mathrm{P}<0.05$ was considered to indicate a statistically significant difference.

\section{Results}

TNFR2 was positively associated with increased tumor size, advanced clinical stage and higher pathological grade. A total of $125 \mathrm{BC}$ specimens were divided into 2 groups, according to TNFR2 expression, resulting in 71 cases with low expression and 54 cases with high expression (Fig. 1). As shown in Table I, only 4 out of 71 cases in the low TNFR2 group had a tumor size $>5 \mathrm{~cm}$, whereas in the high TNFR2 group, a increased number of cases had a tumor size $>5 \mathrm{~cm}$ (12/54 cases; $\mathrm{P}=0.006)$. In total, 12 out of 71 cases in the low TNFR2 group were at stage III, which was significantly less than the 20 out of 54 cases in the high TNFR 2 group $(\mathrm{P}=0.011)$. A total of 5 out of 71 cases in the low TNFR2 group were pathological grade III, which was significantly less than the 14 out of 54 cases in the high TNFR2 group ( $\mathrm{P}=0.004)$. The differences between the two groups in age, menopausal status, family history, lymph node involvement, pathological type, estrogen receptor (ER) or progesterone receptor (PR) status and human epidermal growth factor receptor 2 (HER2) status were not significant. This confirmed the positive association of TNFR2 with larger tumor size, advanced clinical stage and higher pathological grade.

TNFR2 is positively associated with poor prognosis. During the follow-up period, there were 4 mortalities out of the 71 cases in TNFR 2 low expression group, with an OS rate of $94.36 \%$; however, in the TNFR2 high expression group, there were 8 mortalities out of the 54 cases, with an OS rate of $85.18 \%$. In addition, 10 cases of recurrence or metastasis occurred in the TNFR2 low expression group, with a DFS rate of $85.91 \%$, while in the TNFR2 high expression group, 16 cases of recurrence or metastasis occurred, with a DFS rate of $70.37 \%$. Survival rate was estimated using the Kaplan-Meier method and differences were compared using the log-rank test. The differences in OS rate ( $\mathrm{P}=0.0325$; Fig. 1B) and DFS rate $(\mathrm{P}=0.0132$; Fig. $1 \mathrm{C})$ between the two groups were revealed to be significantly different.

Regression analysis of factors affecting OS and DFS rate. To confirm factors that affect the prognosis of patients with $\mathrm{BC}$, Cox regression analysis was performed. Firstly, univariate Cox regression analysis revealed that TNFR2 expression $(\mathrm{P}=0.045)$, tumor size $(\mathrm{P}<0.0001)$, clinical stage $(\mathrm{P}<0.0001)$, pathological grade $(\mathrm{P}=0.002), \mathrm{ER}, \mathrm{PR}$ and HER2 triple-status $(\mathrm{P}=0.001)$ all impacted the OS rate of patients with $\mathrm{BC}$ significantly. In addition, TNFR 2 expression $(\mathrm{P}=0.017)$, age $(\mathrm{P}=0.011)$, menopausal status $(\mathrm{P}<0.0001)$, tumor size $(\mathrm{P}=0.016)$, clinical stage $(\mathrm{P}=0.005)$, pathological grade $(\mathrm{P}=0.002), \mathrm{ER}, \mathrm{PR}$ and HER2 triple-status $(\mathrm{P}=0.008)$ all had an impact on the DFS rate of patients with BC (Table II).

To ascertain the factors effecting prognosis, multivariate Cox regression analysis showed that only clinical stage $(\mathrm{P}=0.024)$ and $\mathrm{ER}, \mathrm{PR}$ and HER 2 triple-status $(\mathrm{P}=0.009)$ showed a significant impact on the OS rate of patients with BC. In addition, only TNFR 2 expression $(\mathrm{P}=0.043)$ and menopausal status $(\mathrm{P}=0.033)$ showed a significant impact on the DFS rate of patients with $\mathrm{BC}$ (Table III).

\section{Discussion}

TNFR2 is encoded by the tumor necrosis factor receptor superfamily 1B (TNFRSF1B) gene (20). In previous years, it was reported that TNFR2 has important roles in the occurrence and progression of various types of tumor, including skin tumors, cholangiocarcinoma, myeloma, colorectal cancer and non-Hodgkin lymphoma (13-17). Jöhrer et al reported that high expression of TNFR 2 promoted the metastasis of myeloma cells (15). Tanimura et al identified 
Table I. Association between tumor necrosis factor receptor 2 and clinical parameters of patients with breast cancer.

\begin{tabular}{|c|c|c|c|c|}
\hline \multirow[b]{2}{*}{ Clinical parameters } & \multirow[b]{2}{*}{ Cases, $\mathrm{n}$} & \multicolumn{2}{|c|}{ TNFR2 expression, $\mathrm{n}$} & \multirow[b]{2}{*}{ P-value } \\
\hline & & Low & High & \\
\hline Total & 125 & 71 & 54 & \\
\hline Age & & & & 0.788 \\
\hline$<35$ years & 40 & 22 & 18 & \\
\hline$\geq 35$ years & 85 & 49 & 36 & \\
\hline Menopausal status & & & & 0.156 \\
\hline No & 49 & 24 & 25 & \\
\hline Yes & 76 & 47 & 29 & \\
\hline Family history & & & & 0.245 \\
\hline No & 105 & 62 & 43 & \\
\hline Yes & 20 & 9 & 11 & \\
\hline Tumor size & & & & $0.006^{\mathrm{a}}$ \\
\hline$<5 \mathrm{~cm}$ & 109 & 67 & 42 & \\
\hline$\geq 5 \mathrm{~cm}$ & 16 & 4 & 12 & \\
\hline Lymph node involvement & & & & 0.188 \\
\hline No & 61 & 31 & 30 & \\
\hline Yes & 64 & 40 & 24 & \\
\hline Clinical stage & & & & $0.011^{\mathrm{a}}$ \\
\hline $\mathrm{I} / \mathrm{II}$ & 93 & 59 & 34 & \\
\hline III & 32 & 12 & 20 & \\
\hline Pathological grade & & & & $0.004^{\mathrm{a}}$ \\
\hline $\mathrm{G} 1 / \mathrm{G} 2$ & 106 & 66 & 40 & \\
\hline G3 & 19 & 5 & 14 & \\
\hline Pathological type & & & & 0.379 \\
\hline Ductal invasive & 84 & 50 & 34 & \\
\hline Others & 41 & 21 & 20 & \\
\hline ER, PR and HER2 status & & & & 0.607 \\
\hline Triple-negative & 33 & 20 & 13 & \\
\hline Non-triple-negative & 92 & 51 & 41 & \\
\hline
\end{tabular}

${ }^{\mathrm{a}} \mathrm{P}<0.05$. TNFR2, tumor necrosis factor receptor 2; ER, estrogen receptor; PR, progesterone receptor; HER2, human epidermal growth factor receptor 2 .

that TNFR2 facilitated invasion of cholangiocarcinoma cells through regulating matrix metalloproteinase 9 secretion (14). A previous study by Mizoguchi et al reported that TNFR2 promoted hyperplasia of mouse colon epithelium and induced carcinomatosis (21). However, clinical studies investigating TNFR2 in BC are limited. In 1997, Jablonska reported that soluble TNF receptors in patients prior to treatment were higher than in the control, and decreased following the surgery treatment (18). In 2000, Tesarová et al reported that plasma levels of soluble TNF receptors may act as a non-specific marker of the untreated BC (19). Xu et al (2014) reported that TNFR2 gene polymorphism in the peripheral blood was associated with risk of BC (20). However, these studies were limited to STNFR2 in BC, but did not investigate TNFR2. In 2005, a study by Mestiri et al demonstrated that the 196R-TNFRII allele showed a significant association with increased OS and DFS in patients with BC (22). This previous study focused on genetic variation in TNFR2, but not TNFR2 itself. In 2006, García-Tuñón et al reported that TNFR2 was higher in in situ carcinoma than in benign breast diseases, and even higher in infiltrating tumors, but no further analysis was performed (23). In the present study, TNFR2 expression was detected in BC tissue using IHC and, to the best of our knowledge, its association with clinical parameters and prognosis was analyzed for the first time. TNFR2 was revealed to be positively associated with increased tumor size, advanced clinical stage and higher pathological grade. This is consistent with the effects of TNFR2 on malignant behaviors of tumor cells reported previously, including proliferation, migration and invasion $(14,24)$.

In addition, survival analysis confirmed that TNFR2 was positively associated with poor OS and DFS rates, in accordance with prognostic effects of the 196R-TNFRII allele. This indicated that TNFR2 has an independent role in 
Table II. Univariate analysis and multivariate analysis identifies factors affecting overall survival of patients with breast cancer.

\begin{tabular}{|c|c|c|c|c|c|c|}
\hline \multirow[b]{2}{*}{ Variables } & \multicolumn{3}{|c|}{ Univariate analysis } & \multicolumn{3}{|c|}{ Multivariate analysis } \\
\hline & RR & $95 \% \mathrm{CI}$ & P-value & RR & $95 \% \mathrm{CI}$ & $\mathrm{P}$-value \\
\hline TNFR2 & 3.428 & $1.03-11.404$ & $0.045^{\mathrm{a}}$ & 3.36 & $0.624-18.107$ & 0.158 \\
\hline Age & 1.012 & $0.273-3.755$ & 0.986 & 1.962 & $0.373-10.303$ & 0.426 \\
\hline Menopausal status & 0.374 & $0.119-1.172$ & 0.091 & 1.073 & $0.126-9.125$ & 0.948 \\
\hline Family history & 0.672 & $0.182-2.483$ & 0.551 & 2.315 & $0.398-13.472$ & 0.35 \\
\hline Tumor size & 16.156 & $4.821-54.138$ & $<0.0001^{\mathrm{a}}$ & 0.256 & $0.047-1.407$ & 0.117 \\
\hline Lymph involvement & 2.493 & $0.674-9.215$ & 0.171 & 0.425 & $0.065-2.79$ & 0.373 \\
\hline Clinical stage & 11.743 & $3.147-43.823$ & $<0.0001^{\mathrm{a}}$ & 0.071 & $0.007-0.703$ & $0.024^{\mathrm{a}}$ \\
\hline Pathological grade & 6.48 & 2.04-20.584 & $0.002^{\mathrm{a}}$ & 0.371 & $0.057-2.395$ & 0.297 \\
\hline Histological type & 1.347 & $0.427-4.245$ & 0.611 & 0.132 & $0.014-1.271$ & 0.08 \\
\hline ER, PR and HER2 & 7.448 & $2.236-24.804$ & $0.001^{\mathrm{a}}$ & 0.077 & $0.011-0.53$ & $0.009^{\mathrm{a}}$ \\
\hline
\end{tabular}

${ }^{\mathrm{a}} \mathrm{P}<0.05$. TNFR2, tumor necrosis factor receptor 2; ER, estrogen receptor; PR, progesterone receptor; HER2, human epidermal growth factor receptor 2; RR, relative risk; CI, confidence interval.

A

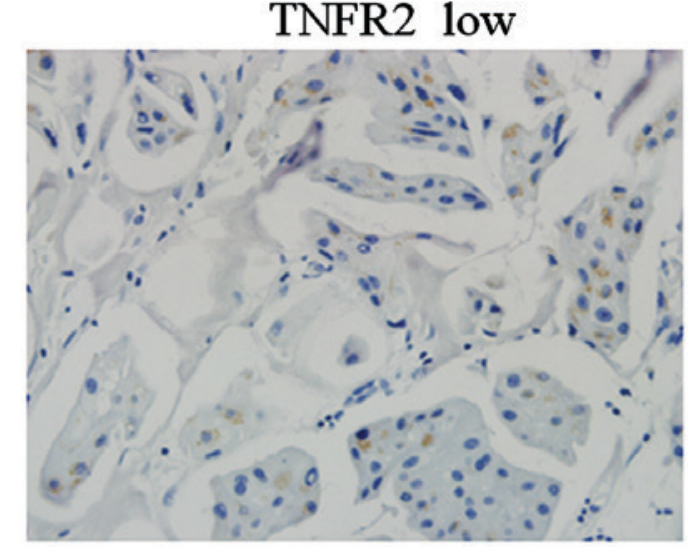

B

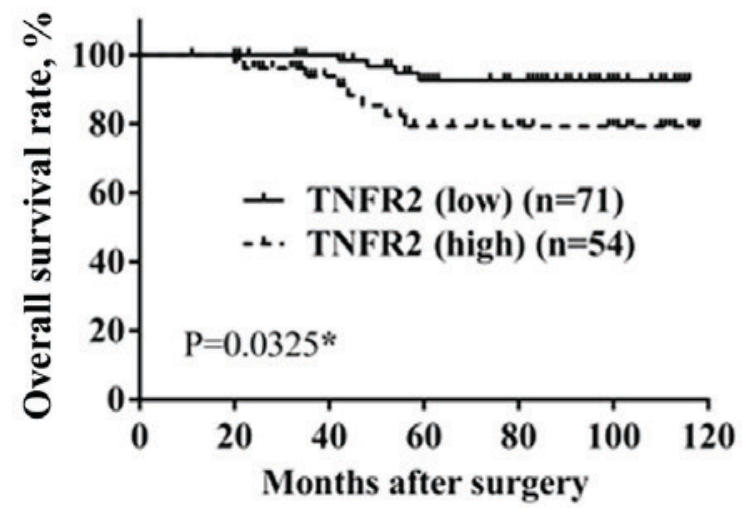

TNFR2 high

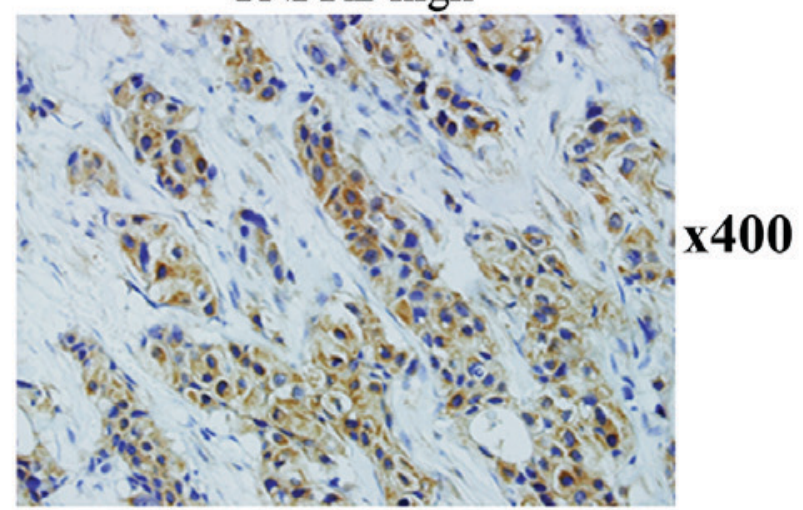

C

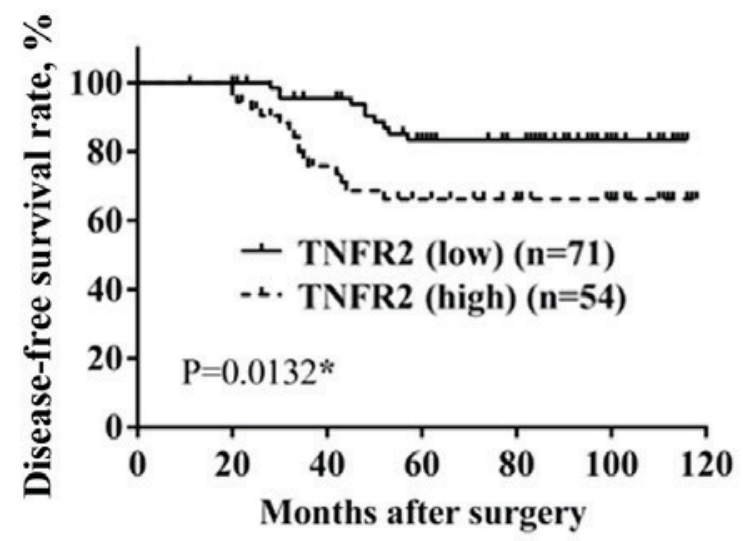

Figure 1. TNFR2 expression in BC tissue and its association with OS and DFS rate. (A) TNFR2 expression in BC tissue by immunohistochemical staining. (B) Comparison of OS rate between TNFR2 low group and TNFR2 high group. (C) Comparison of DFS rate between TNFR2 low group and TNFR2 high group. BC, breast cancer; OS, overall survival; DFS, disease-free survival; TNFR2, tumor necrosis factor receptor 2.

predicting the prognosis of BC. During the follow-up period, almost all patients accepted different types of adjuvant therapies, including chemotherapy, radiotherapy, immunomodulatory therapy and even Chinese herbal therapy.
According to ER, PR and HER2 status and economical capability, patients accepted hormonal therapy or molecular target therapy to a different degree. All the treatments may play a role in prognosis. However, the present study aimed 
Table III. Univariate analysis and multivariate analysis identifies factors affecting disease-free survival of patients with breast cancer.

\begin{tabular}{|c|c|c|c|c|c|c|}
\hline \multirow[b]{2}{*}{ Variables } & \multicolumn{3}{|c|}{ Univariate analysis } & \multicolumn{3}{|c|}{ Multivariate analysis } \\
\hline & RR & $95 \% \mathrm{CI}$ & P-value & RR & $95 \% \mathrm{CI}$ & P-value \\
\hline TNFR2 & 2.616 & $1.185-5.775$ & $0.017^{\mathrm{a}}$ & 2.622 & $1.031-6.668$ & $0.043^{\mathrm{a}}$ \\
\hline Age & 2.723 & $1.258-5.895$ & $0.011^{\mathrm{a}}$ & 2.033 & $0.797-5.19$ & 0.138 \\
\hline Menopausal status & 4.324 & $1.916-9.759$ & $<0.0001^{\mathrm{a}}$ & 3.41 & $1.103-10.544$ & $0.033^{\mathrm{a}}$ \\
\hline Family history & 0.875 & $0.301-2.541$ & 0.806 & 1.232 & $0.374-4.054$ & 0.732 \\
\hline Tumor size & 0.344 & $0.144-0.82$ & $0.016^{\mathrm{a}}$ & 0.847 & $0.28-2.561$ & 0.769 \\
\hline Lymph involvement & 1.351 & $0.625-2.921$ & 0.444 & 0.73 & $0.26-2.054$ & 0.551 \\
\hline Clinical stage & 0.328 & $0.15-0.714$ & $0.005^{\mathrm{a}}$ & 0.442 & $0.158-1.241$ & 0.121 \\
\hline Pathological grade & 0.257 & $0.111-0.595$ & $0.002^{\mathrm{a}}$ & 0.596 & $0.225-1.574$ & 0.296 \\
\hline Histological type & 1.407 & $0.466-2.349$ & 0.912 & 0.949 & $0.393-2.291$ & 0.908 \\
\hline ER, PR and HER2 & 2.856 & $1.318-6.187$ & $0.008^{\mathrm{a}}$ & 0.615 & $0.238-1.588$ & 0.315 \\
\hline
\end{tabular}

${ }^{\mathrm{a}} \mathrm{P}<0.05$. TNFR2, tumor necrosis factor receptor 2; ER, estrogen receptor; PR, progesterone receptor; HER2, human epidermal growth factor receptor 2; RR, relative risk; $\mathrm{CI}$, confidence interval.

to analyze the roles of TNFR2 in prognosis. Therefore, the association of all the adjuvant therapies with prognosis was not investigated.

$\mathrm{BC}$ is a complicated disease and its prognosis may be effected by different factors, including age, menopausal status, clinical stage, pathological grade and receptors on the tumor cell surface (25-27). Tumor cells at an advanced stage usually possess higher malignant behaviors, including proliferation, migration, invasion and drug resistance, and lose surgery opportunity, resulting in poor prognosis $(28,29)$. Triple negative $\mathrm{BC}$ (TNBC) is a distinct subgroup of $\mathrm{BC}$ that has been shown to exhibit negative ER, PR and HER2 expression, and was characterized by more aggressive behavior compared with non-TNBC (30). In addition, patients lacking expression of ER, PR and HER2 cannot benefit from endocrine therapy and molecular targeted treatments for HER2, which is effective for ameliorating prognosis $(6,7,31)$. In the present study, univariate and multivariate Cox regression showed that clinical stage and ER, PR and HER2 triple-status may significantly impact the OS rate of patients with BC. Univariate and multivariate Cox regression showed also that TNFR2 expression and menopausal status may significantly impact the DFS rate of patients with BC. This can be explained by the important role of estrogen in $\mathrm{BC}$ occurrence and the impact of TNFR 2 on malignant behaviors of tumor cells.

However, the present study had certain deficiencies. Since all the samples were from local patients, data evidently had regional limitation and the results could not embody the implication of TNFR2 universally. Furthermore, only 125 BC samples were involved, and the limited number of cases also restricted the reliability of the present study. In addition, establishment of a validation cohort may make the results more convincing.

In conclusion, the present study verified the important roles of TNFR2 in progression and prognosis of BC and enriched the understanding of the roles of TNFR2 as an effective target for BC therapy.

\section{References}

1. Riaz SK, Saeed M and Malik MF: Clinical and therapeutic implications of histone acetylation in breast cancer. West Indian Med J: May 6, 2015 (Epub ahead of print).

2. Strasser-Weippl K, Horick N, Smith IE, O'Shaughnessy J, Ejlertsen B, Boyle F, Buzdar AU, Fumoleau P, Gradishar W, Martin M, et al: Identification of early breast cancer patient cohorts who may benefit from lapatinib therapy. Eur J Cancer 56: 85-92, 2016.

3. Sage EK, Schmid TE, Sedelmayr M, Gehrmann M, Geinitz H, Duma MN, Combs SE and Multhoff G: Comparative analysis of the effects of radiotherapy versus radiotherapy after adjuvant chemotherapy on the composition of lymphocyte subpopulations in breast cancer patients. Radiother Oncol 118: 176-180, 2016.

4. Smoot B, Paul SM, Aouizerat BE, Dunn L, Elboim C, Schmidt B, Hamolsky D, Levine JD, Abrams G, Mastick J, et al: Predictors of altered upper extremity function during the first year after breast cancer treatment. Am J Phys Med Rehabil 95: 639-655, 2016.

5. Partridge AH: Chemotherapy in premenopausal breast cancer patients. Breast Care (Basel) 10: 307-310, 2015.

6. Zhu YY, Si W, Ji TF, Guo XQ, Hu Y and Yang JL: The variation and clinical significance of hormone receptors and Her-2 status from primary to metastatic lesions in breast cancer patients. Tumour Biol 37: 7675-7684, 2016.

7. Lin PL, Hao Y, Xie J, Li N, Zhong Y, Zhou Z, Signorovitch JE and Wu EQ: Physician experiences and preferences in the treatment of HR+/HER2- metastatic breast cancer in the United States: A physician survey. Cancer Med 5: 209-220, 2016.

8. Rossi L and Pagani O: The modern landscape of endocrine therapy for premenopausal women with breast cancer. Breast Care (Basel) 10: 312-315, 2015.

9. Hosono K, Yamada E, Endo H, Takahashi H, Inamori M, Hippo Y, Nakagama $\mathrm{H}$ and Nakajima A: Increased tumor necrosis factor receptor 1 expression in human colorectal adenomas. World $\mathrm{J}$ Gastroenterol 18: 5360-5368, 2012.

10. Tang W, Lu Y, Tian QY, Zhang Y, Guo FJ, Liu GY, Syed NM, Lai Y, Lin EA, Kong L, et al: The growth factor progranulin binds to TNF receptors and is therapeutic against inflammatory arthritis in mice. Science 332: 478-484, 2011.

11. Guo Z, Li Q, Han Y, Liang Y, Xu Z and Ren T: Prevention of LPS-induced acute lung injury in mice by progranulin. Mediators Inflamm 2012: 540794, 2012.

12. Zhao YP, Tian Q, Frenkel S and Liu CJ: The promotion of bone healing by progranulin, a downstream molecule of BMP-2, through interacting with TNF/TNFR signaling. Biomaterials 34 : 6412-6421, 2013 
13. Arnott CH, Scott KA, Moore RJ, Robinson SC, Thompson RG and Balkwill FR: Expression of both TNF-alpha receptor subtypes is essential for optimal skin tumour development. Oncogene 23: 1902-1910, 2004.

14. Tanimura Y, Kokuryo T, Tsunoda N, Yamazaki Y, Oda K, Nimura Y, Naing Mon N, Huang P, Nakanuma Y, Chen MF, et al: Tumor necrosis factor alpha promotes invasiveness of cholangiocarcinoma cells via its receptor, TNFR2. Cancer Lett 219: 205-213, 2005.

15. Jöhrer K, Janke K, Krugmann J, Fiegl M and Greil R: Transendothelial migration of myeloma cells is increased by tumor necrosis factor (TNF)-alpha via TNF receptor 2 and autocrine up-regulation of MCP-1. Clin Cancer Res 10: 1901-1910, 2004.

16. Grotowski M and Wojtuń S: CEA, CA-19-9 and il-8, sTNFRII and sil-2R in persons at high risk of colorectal cancer. Pol Merkur Lekarski 14: 327-330, 2003 (In Polish).

17. Heemann C, Kreuz M, Stoller I, Schoof N, von Bonin F, Ziepert M, Löffler M, Jung W, Pfreundschuh M, Trümper L and Kube D: Circulating levels of TNF receptor II are prognostic for patients with peripheral T-cell non-Hodgkin lymphoma. Clin Cancer Res 18: 3637-3647, 2012.

18. Jablonska E: Release of soluble IL-6 receptor (IL-6sR) in comparison with release of soluble TNF receptors (sTNF-Rs) by PMNs and WBC derived from breast cancer patients. Cancer Lett 119: 79-85, 1997.

19. Tesarová P, Kvasnicka J, Umlaufová A, Homolková H, Jirsa M and Tesar V: Soluble TNF and IL-2 receptors in patients with breast cancer. Med Sci Monit 6: 661-667, 2000.

20. Xu F, Zhou G, Han S, Yuan W, Chen S, Fu Z, Li D, Zhang H, Li D and Pang D: Association of TNF- $\alpha$, TNFRSF1A and TNFRSF1B gene polymorphisms with the risk of sporadic breast cancer in northeast Chinese Han women. PLoS One 9: e101138, 2014.

21. Mizoguchi E, Mizoguchi A, Takedatsu H, Cario E, de Jong YP, Ooi CJ, Xavier RJ, Terhorst C, Podolsky DK and Bhan AK: Role of tumor necrosis factor receptor 2 (TNFR2) in colonic epithelial hyperplasia and chronic intestinal inflammation in mice. Gastroenterology 122: 134-144, 2002.

22. Mestiri S, Bouaouina N, Ben Ahmed S and Chouchane L: A functional polymorphism of the tumor necrosis factor receptor-II gene associated with the survival and relapse prediction of breast carcinoma. Cytokine 30: 182-187, 2005.
23. García-Tuñón I, Ricote M, Ruiz A, Fraile B, Paniagua R and Royuela M: Role of tumor necrosis factor-alpha and its receptors in human benign breast lesions and tumors (in situ and infiltrative). Cancer Sci 97: 1044-1049, 2006

24. Yang D, Wang LL, Dong TT, Shen YH, Guo XS, Liu CY, Liu J, Zhang P, Li J and Sun YP: Progranulin promotes colorectal cancer proliferation and angiogenesis through TNFR2/Akt and ERK signaling pathways. Am J Cancer Res 5: 3085-3097, 2015.

25. Mouttet D, Laé M, Caly M, Gentien D, Carpentier S, Peyro-Saint-Paul H, Vincent-Salomon A, Rouzier R, Sigal-Zafrani B, Sastre-Garau X and Reyal F: Estrogen-receptor, progesterone-receptor and HER2 status determination in invasive breast cancer. Concordance between immuno-histochemistry and MapQuant microarray based assay. PLoS One 11: e0146474, 2016.

26. Pizot C, Boniol M, Mullie P, Koechlin A, Boniol M, Boyle P and Autier P: Physical activity, hormone replacement therapy and breast cancer risk: A meta-analysis of prospective studies. Eur J Cancer 52: 138-154, 2016.

27. Jemal A, Bray F, Center MM, Ferlay J, Ward E and Forman D Global cancer statistics. CA Cancer J Clin 61: 69-90, 2011.

28. Chai P, Tian J, Zhao D, Zhang H, Cui J, Ding K and Liu B: GSE1 negative regulation by miR-489-5p promotes breast cancer cell proliferation and invasion. Biochem Biophys Res Commun 471: 123-128, 2016.

29. Richards P, Ward S, Morgan J, Lagord C, Reed M, Collins K and Wyld L: The use of surgery in the treatment of ER+ early stage breast cancer in England: Variation by time, age and patient characteristics. Eur J Surg Oncol 42: 489-496, 2016.

30. Qiu J, Xue X, Hu C, Xu H, Kou D, Li R and Li M: Comparison of clinicopathological features and prognosis in triple-negative and non-triple negative breast cancer. J Cancer 7: 167-173, 2016.

31. Ingthorsson S, Andersen K, Hilmarsdottir B, Maelandsmo GM, Magnusson MK and Gudjonsson T: HER2 induced EMT and tumorigenicity in breast epithelial progenitor cells is inhibited by coexpression of EGFR. Oncogene 35: 4244-4255, 2016. 